\title{
Including More Information Content to Enhance the Value at Risk Estimation for Real Estate Investment Trusts
}

\author{
Jin-Ray Lu ${ }^{1}$, Chiang-Chang Hwang ${ }^{1}$, Yi-Chun Chen ${ }^{1} \&$ Chu-Ting Wen ${ }^{1}$ \\ ${ }^{1}$ Department of Finance, National Dong Hwa University, Hualien, Taiwan, R.O.C \\ Correspondence: Jin-Ray Lu, Department of Finance, National Dong Hwa University, 1, Section 2, University Rd. \\ Shou-Feng, Hualien 974, Taiwan, R.O.C. Tel: 886-3-863-3140. E-mail: jinray@mail.ndhu.edu.tw
}

Received: May 23, 2013

Accepted: June 14, 2013

Online Published: June 24, 2013

doi:10.5430/ijfr.v4n3p25

URL: http://dx.doi.org/10.5430/ijfr.v4n3p25

\begin{abstract}
This article designs two improved methods to estimate the value at risk (VaR) for US real estate investment trusts (REITs) and specifically considers some higher moments of asset returns and composite methods which are combined with existing models. Our empirical results indicate that accounting for higher moments of REITs returns does not produce better VaR estimates. On the contrary, the composite methods can considerably enhance the REIT VaR estimation. These findings indicate that the information provided by the composite methods is better than that provided by considering higher moments.
\end{abstract}

Keywords: REITs, VaR, composite method, higher moments

\section{Introduction}

The appearance of the US sub-prime mortgage market crisis and the EURO crisis had enormous impacts on global capital markets, banking systems, and national economies. Thus, risk management has gradually increased in importance for market participators. Since the US crisis originated from the real estate industry, risk management in the real estate industry is obviously required, and thus this study proposes alternative models for producing better Value-at-Risk (VaR) measurements of real estate investment trusts (REITs). REIT investors can apply VaRs to measure, evaluate, and manage their maximum possible losses as financial crises appear. Although REITs have little risk compared with equities and derivatives, the impact of financial events on the REITs is also obvious. (e.g., Ewing and Payne 2005; Gordon and Tse 2003; Lu et al. 2009; Lu et al. 2013) This study attempts to design new methods for calculating VaRs, to increase the reliability of measurement tools. Therefore, this article contributes to the real estate finance literature on new methods of calculating value at risk.

Practitioners and academics have developed, compared, and evaluated alternative models for calculating VaRs. (e.g., Brooks and Persand, 2002; Engle and Manganelli, 2004; Kuester et al., 2006; Ouyang, 2009; Lu et al. 2013; Dias 2013) For example, Komunjer (2007) compared the performances of VaR forecasts based on various GARCH-type models, and found that such performances depended on confidence levels. Ouyang (2009) found that a complicated model performed better than other simpler models. Lu et al. (2009) found that the REIT VaR varied among individual portfolios, and the individual model performance differed among confidence levels. Dias (2013) specifically stressed on the role of market capitalization in the estimation of VaR for providing a market fundamentals related to a risk measurement.

Based on the mixed results of the various empirical studies outlined above, researchers have so far failed to find an optimal VaR model. Therefore it is still necessary to develop another reliable tool for VaR calculation. In particular, it also remains to re-identify an optimal model of VaR estimation to specially fit the real estate industry. This investigation attempts to improve the efficiency of estimating VaRs through the development of some statistical methods.

Numerous empirical studies have observed the dynamic behavior of asset returns and their tendency to display volatility clustering. Engle (1982) and Bollerslev (1986) considered the characteristics of volatility clustering and developed a GARCH model to fit stock returns. However, the proposed GARCH model handles only time-varying mean returns and variances, and considers two moments within the return series. Harvey and Siddique (1999) extended the proposed GARCH model and presented a method for estimating volatility based on the time-varying 
skewness. Leon et al. (2005) subsequently proposed a GARCH-type model that allowed for time-varying third and fourth moments by applying a Gram-Charlier series expansion of a normal density function for the error term, in which this GARCH-type model capturing higher moments of asset returns exhibits complete fits for asset volatility.

Numerous studies have demonstrated that the distribution of REIT returns exhibited asymmetric clustering (see, Devaney, 2001; Bond and Patel, 2003; Lee and Ou, 2010; Zhou, 2012, Lu, et al. 2013). The non-normality feature of REIT returns drives us to consider using GARCH type models with time-varying third and fourth moments to estimate REIT VaRs in this paper. The existing literature has not estimated the VaRs using GARCH models accounting for higher moments of asset returns.

Additionally, numerous studies have demonstrated that the composite methods for variable forecasting or estimating are superior to individual models (see, Bates and Granger, 1969; Granger and Ramanathan, 1984; Shi et al., 1999; Charles, 2000). The composite methods can integrate more information content from each model into one model, and thus provide more accurate forecasts. Charles (2000) found that when combined in different ways, the results from composite forecasting methods were more accurate and less error prone than those seen from individual models. Still, such methods have never been used to estimate VaRs in the real estate industry.

The empirical results of previous VaR studies in the real estate industry were inconsistent. Thus, this study discusses some specific methods for improving REIT VaR estimation in the US real estate industry over the period 1981-2011. The first method considers that the time-varying higher moments incorporate more information on asset returns, and are factored into GARCH-type models for the VaR estimation. The second method considers the composites of alternative models to further increase the efficiency estimation of REIT VaRs.

The remainder of this paper is organized as follows. Section II outlines several models used to estimate VaR, together with model selection procedures, and sample descriptions. Section III presents empirical evidence regarding REIT stocks. Section IV concludes the article.

\section{Models and Methodologies}

This section proposes several models for estimating the REIT VaRs, explains the evaluated indicators for model comparisons, and describes the empirical sample used for this analysis.

\subsection{Value at Risk Estimation Methods}

The value at risk is defined as the biggest loss which may occur to an asset portfolio during a certain period $\Delta t$ at a given confidence level 1- $\alpha \%$. Assume that $r_{t}$ denotes the asset return during a period of $t$ days. At a given confidence level of $1-\alpha \%$, this work finds a threshold limit value $r^{*}$ under a given return distribution.

$$
\operatorname{Prob}\left(r_{t}<-V a R\right)=\alpha \%
$$

Under the assumption of normality in asset returns, the value-at-risk can be expressed as follows:

$$
V a R=V \times Z_{\alpha} \times \sigma \times \sqrt{\Delta t}
$$

where $V$ denotes the initial value of asset investment. $Z_{\alpha}$ represents the $\alpha$ percentile of standard normal distribution, and $\sigma$ is the return volatility.

The first model is a historical simulation that directly observes the previous empirical distribution of a portfolio or individual assets. We obtain VaRs from the historical simulation as follows. First, we identify adequate sample data and determine the observation window length. For example, assume $n$ weekly data, and $m$ window lengths. We then calculate the weekly returns for $m$ weeks and sort them from smallest to largest. We first calculate the VaR by choosing relative locations from $\hat{R}_{1}$ to $\hat{R}_{m}$. The $5 \%$-VaR and $1 \%$-VaR comprise the $\mathrm{m} / 20^{\text {th }}$ and $\mathrm{m} / 100^{\text {th }}$ smallest observations in the window lengths, respectively. Furthermore, we calculate the second VaR by choosing relative locations from $\hat{R}_{2}$ to $\hat{R}_{m+1}$ and calculate the third VaR by selecting relative locations from $\hat{R}_{3}$ to $\hat{R}_{m+2}$, and repeat these procedures until all the sample data are consumed. The $(n-m)$ VaRs are thus obtained.

The second model is the Monte Carlo simulation, and involves three steps, as follows. First, we simulate the 
fictitious price paths for the considered assets using a random number generator based on the Geometric Brownian Motion (GBM). Second, we construct an asset return distribution using the simulated price paths and calculate the VaRs for a given confidence level. This work assumes that the REIT price $\left(S_{t}\right)$ as described by GBM could be described using the following discrete process:

$$
\Delta S_{t}=S_{t-1}\left(\mu_{t} \Delta t+\sigma_{t} \varepsilon \sqrt{\Delta t}\right)
$$

where $\mu_{t}$ and $\sigma_{t}$ represent the expected return rate and the volatility rate of the REIT price. $\varepsilon$ represents a randomly available normal distribution with a mean of zero and a unit variance, and $\Delta t$ represents the holding days. Finally, we estimate the asset return volatility from the simulated price path and further obtain VaRs through equation (3).

The third model is an exponentially weighted moving average (EWMA) model developed by J. P. Morgan (1996) that measures the VaRs and is widely used in practice. EWMA also assigns recent observations a heavier weight, according to which the past information will reflect the present returns. The return variance for a one-forward-step prediction measured by the EWMA is represented as follows:

$$
\sigma_{t}^{2}=\lambda \sigma_{t-1}^{2}+(1-\lambda) r_{t-1}^{2}
$$

where $\lambda$ represents a decay factor between 0 and 1 . In this study, $\lambda$ is 0.94 for weekly data, as suggested by J. P. Morgan.

The fourth method uses the GARCH model which allows for a time-varying second moment (volatility), third moment (skewness), and fourth moment (kurtosis) of asset returns based on the GARCH $(1,1)$ structure. This model has the following form:

$$
\begin{gathered}
r_{t}=\alpha_{0}+\alpha_{1} r_{t-1}+\varepsilon_{t} \\
\varepsilon_{t}=\sqrt{h}_{t} \eta_{t}, \quad \eta_{t} \approx N(0,1) \\
h_{t}=\beta_{0}+\beta_{1} \varepsilon_{t-1}^{2}+\beta_{2} h_{t-1} \\
s_{t}=\gamma_{0}+\gamma_{1} \varepsilon_{t-1}^{3}+\gamma_{2} s_{t-1} \\
k_{t}=\delta_{0}+\delta_{1} \varepsilon_{t-1}^{4}+\delta_{2} k_{t-1}
\end{gathered}
$$

where $h_{t}, s_{t}$, and $k_{t}$ denote the second moment (variance), third moment (skewness), and fourth moment (kurtosis) of conditional returns $r_{t}$ of asset $i$ for period $t$, respectively. Furthermore, $\varepsilon_{i t}$ is a disturbance term with a mean of zero and serially independent and homoskedastic variance. This study uses a Gram-Charlier (GC) series expansion of the normal density function which was truncated at the fourth moment to yield the following density function for standardized residuals dependent on information available at time $t-1$.

$$
f\left(\eta_{t} \mid I_{t-1}\right)=\varphi\left(\eta_{t}\right)\left[1+\frac{s_{t}}{3 !}\left(\eta_{t}^{3}-3 \eta_{t}\right)+\frac{k_{t}-3}{4 !}\left(\eta_{t}^{4}-6 \eta_{t}^{2}+3\right)\right]
$$

where $\varphi(\cdot)$ denotes the normal density function.

Finally, we develop composite models to enhance the reliability of the REIT VaR estimations, in which the GARCH model is combined with a Monte Carlo simulation, a historical simulation, and an EWMA. We weight these models with the simple average weight or the root mean squared error (RMSE) weight methods. Our aim is not to find an optimal composite weight for form composite methods, but rather to use the composite method to estimate VaRs for 
the purpose of evaluating whether the composite method outperforms those of individual models.

Among the simplest composite methods are the simple average weighted methods that are equally weighted for various models. The second composite method uses the root mean squared error to be the weight of several models. Since Granger and Ramanathan (1984) had documented that the composite methods weighted with RMSE are accurate, this study establishes models in which the value of the root mean squared error is minimized, where the RMSE denotes the distance between actual returns and the estimated VaR.

$$
R M S E_{k}=\sqrt{\frac{1}{m} \sum_{t=1}^{m}\left(R_{t, k}-V a R_{t, k}\right)^{2}}
$$

where $m$ denotes the window size, $R_{t, k}$ represents the actual daily returns at time $t$ for an individual model $k$, and $V a R_{t, k}$ is the estimated VaRs at time $t$ for an individual model. The weight of individual models in this composite method is as follows:

$$
w_{k}=\frac{\frac{1}{R M S E_{k}}}{\frac{1}{R M S E_{1}}+\frac{1}{R M S E_{2}}+\ldots+\frac{1}{R M S E_{N}}}, \sum_{i=1}^{N} w_{i}=1
$$

This study employs two composite models to improve the VaR estimation, in which we integrate the information content into a composite model.

\subsection{Model Evaluation}

An average absolute failure error (AAFE) and a root mean squared relative bias (RMSRB) are adopted as statistical indicators for a one-step-ahead forecasting comparison. We determine an optimal method for estimating the REIT VaRs by finding the smallest failure error or bias. This study searches failure events from 2011 in which actual returns were less than or equal to the $99 \%$ or $95 \%$ one-step-ahead forecasted VaRs. The root mean squared relative bias, as presented by Hendricks (1996), can measure the distance between the estimated and average VaRs of all models.

$$
\operatorname{RMSRB}_{i}=\sqrt{\frac{1}{T} \sum_{i=1}^{T}\left(N \times V a R_{i t}-\sum_{j=1}^{N} \operatorname{VaR}_{j t}\right) / \sum_{j=1}^{N} \operatorname{VaR}_{j t}}
$$

where $T$ denotes the sample size and $N$ represents the model number.

Having these error indicators, we implement a student's $t$-test procedure to evaluate the mean differences of forecasting performances for these models. Thus, we can answer the question of whether the two improved methods, which are first employed on the REIT VaR issues, outperform the traditional models such as simulation models, EWMA, and so forth.

\subsection{Empirical Sample}

This study examines American publicly listed real estate investment trusts in which the empirical sample is comprised of weekly closing levels (Monday to Friday) for the period from January 1981 to December 2011. These REITs were downloaded from the DataStream and classified based on their properties. Initially the sample contained 132 firms, but some firms that had been trading for less than three years were excluded. Overall, this study obtained a reasonably sized sample of 122 REITs during the holding period. These were grouped into seven portfolios which are as follows: diversified, healthcare, hotel/motel, industrial, office, residential, and retail. A return rate for each REIT was calculated as the $\log$ of the price differences. 
Table 1. Estimated one-week REIT value-at-risk by individual models

\begin{tabular}{|c|c|c|c|c|c|c|}
\hline & GARCH 1 & GARCH2 & GARCH3 & EWMA & HS & $\mathrm{MC}$ \\
\hline \multicolumn{7}{|c|}{ Panel A: Property group at the $99 \%$ confidence level } \\
\hline All REITs (122) & 0.1151 & 0.6242 & 0.3002 & 0.0209 & 0.1203 & 0.1092 \\
\hline Diversified (23) & 0.1025 & 1.5031 & 0.3423 & 0.0238 & 0.1146 & 0.1251 \\
\hline Healthcare(11) & 0.1029 & 0.6231 & 0.2989 & 0.0182 & 0.0802 & 0.0598 \\
\hline Hotel/Motel(10) & 0.1361 & 0.3790 & 0.2729 & 0.0242 & 0.1401 & 0.1245 \\
\hline Industrial(11) & 0.0950 & 0.3103 & 0.2552 & 0.0125 & 0.0829 & 0.0730 \\
\hline Office(14) & 0.1739 & 0.2908 & 0.3242 & 0.0330 & 0.1432 & 0.1245 \\
\hline Residential (19) & 0.1254 & 0.2889 & 0.2530 & 0.0298 & 0.1145 & 0.0837 \\
\hline Retail (34) & 0.1263 & 0.8130 & 0.3180 & 0.0210 & 0.1066 & 0.1284 \\
\hline \multicolumn{7}{|c|}{ Panel B: Property group at the $95 \%$ confidence level } \\
\hline All REITs & 0.0802 & 0.4152 & 0.2105 & 0.0135 & 0.0688 & 0.0697 \\
\hline Diversified & 0.0836 & 1.1134 & 0.2366 & 0.0141 & 0.0701 & 0.0783 \\
\hline Healthcare & 0.0549 & 0.3407 & 0.1830 & 0.0120 & 0.0626 & 0.0540 \\
\hline Hotel/Motel & 0.0921 & 0.2130 & 0.1720 & 0.0167 & 0.0792 & 0.0801 \\
\hline Industrial & 0.0671 & 0.1845 & 0.1987 & 0.0089 & 0.0460 & 0.0514 \\
\hline Office & 0.1430 & 0.2301 & 0.1793 & 0.0174 & 0.0899 & 0.0871 \\
\hline Residential & 0.0697 & 0.1819 & 0.1688 & 0.0125 & 0.0712 & 0.0751 \\
\hline Retail & 0.0726 & 0.5102 & 0.2037 & 0.0109 & 0.0583 & 0.0527 \\
\hline
\end{tabular}

Notes: The sample frequency is shown in parentheses in Panel A. The GARCH1, GARCH2, and GARCH3 represented GARCH models allowing for time-varying higher moments up to the second, third, and fourth moments, respectively.

\section{Empirical Results}

The statistical characteristics of VaRs generated from individual models are analyzed first, followed by a comparison of the relative superiority of alternative models.

\subsection{Value at Risk Estimates}

The estimated VaRs for REITs over a full sample period are shown in Table 1, which shows reported average weekly VaRs at the $95 \%$ and $99 \%$ confidence levels for the seven REIT property groups. In Table 1, the GARCH1, GARCH2, and GARCH3 represented GARCH models allowing for time-varying higher moments up to the second, third, and fourth moments, respectively. This study selects 100 weeks as an estimated window length for these parameters in the historical simulation and EWMA model, and 10,000 simulations are performed for the Monte Carlo procedure. As a result, this study found that the VaRs were largest when we used the GARCH2 (which considered second and third moments of asset returns), and smallest when we used the EWMA for most groups at the 95\% and 99\% confidence levels, respectively. Additionally, the office REITs group had the largest estimated VaR based on various models at the $95 \%$ and $99 \%$ confidence levels, demonstrating that this group faced a higher market risk and larger losses. The results imply that the VaRs vary by REIT classes and estimated methods as shown in Table 1. 
Table 2. Estimated one-week REIT value-at-risk varied by year

\begin{tabular}{|c|c|c|c|c|c|c|c|}
\hline \multicolumn{8}{|c|}{ Panel A: At 99\% confidence level } \\
\hline & Diversified & Healthcare & Hotel & Industrial & Office & Residential & Retail \\
\hline \multicolumn{8}{|l|}{ EWMA } \\
\hline 1981-1985 & 0.0165 & 0.0125 & 0.0160 & 0.0138 & 0.0057 & 0.0126 & 0.0139 \\
\hline $1986-1990$ & 0.0204 & 0.0143 & 0.0226 & 0.0121 & 0.0161 & 0.0168 & 0.0169 \\
\hline 1991-1995 & 0.0185 & 0.0119 & 0.0208 & 0.0182 & 0.0237 & 0.0164 & 0.0131 \\
\hline $1996-2000$ & 0.0131 & 0.0163 & 0.0148 & 0.0134 & 0.0253 & 0.0149 & 0.0136 \\
\hline 2001-2005 & 0.0109 & 0.0160 & 0.0157 & 0.0113 & 0.0124 & 0.0138 & 0.0135 \\
\hline 2006-2011 & 0.0281 & 0.0485 & 0.0462 & 0.0347 & 0.0305 & 0.0433 & 0.0179 \\
\hline \multicolumn{8}{|l|}{ HS } \\
\hline 1981-1985 & 0.1192 & 0.0508 & 0.0812 & 0.0710 & 0.0543 & 0.0732 & 0.0789 \\
\hline 1986-1990 & 0.1126 & 0.1043 & 0.1154 & 0.0963 & 0.0998 & 0.0886 & 0.1013 \\
\hline 1991-1995 & 0.1199 & 0.0672 & 0.1383 & 0.0705 & 0.1362 & 0.0823 & 0.0782 \\
\hline $1996-2000$ & 0.0729 & 0.0865 & 0.1144 & 0.0684 & 0.0873 & 0.0659 & 0.0723 \\
\hline 2001-2005 & 0.0739 & 0.1032 & 0.1039 & 0.0683 & 0.0639 & 0.0683 & 0.0974 \\
\hline 2006-2011 & 0.1307 & 0.1153 & 0.1454 & 0.0960 & 0.1128 & 0.1461 & 0.1310 \\
\hline \multicolumn{8}{|l|}{$\mathrm{MC}$} \\
\hline 1981-1985 & 0.1011 & 0.0537 & 0.0863 & 0.0726 & 0.0675 & 0.0758 & 0.0794 \\
\hline 1986-1990 & 0.1060 & 0.0784 & 0.0880 & 0.0769 & 0.0832 & 0.0872 & 0.0811 \\
\hline 1991-1995 & 0.1119 & 0.0626 & 0.1291 & 0.0658 & 0.1662 & 0.0734 & 0.0745 \\
\hline $1996-2000$ & 0.0935 & 0.0753 & 0.0966 & 0.0557 & 0.0838 & 0.0619 & 0.0775 \\
\hline $2001-2005$ & 0.0756 & 0.0917 & 0.0971 & 0.0583 & 0.0587 & 0.0616 & 0.0752 \\
\hline $2006-2011$ & 0.1397 & 0.0869 & 0.1236 & 0.0911 & 0.1463 & 0.0975 & 0.1337 \\
\hline \multicolumn{8}{|c|}{ Panel B: At 95\% confidence level } \\
\hline \multicolumn{8}{|l|}{ EWMA } \\
\hline 1981-1985 & 0.0128 & 0.0082 & 0.0121 & 0.0151 & 0.0039 & 0.0081 & 0.0087 \\
\hline 1986-1990 & 0.0171 & 0.0133 & 0.0154 & 0.0094 & 0.0143 & 0.0112 & 0.0115 \\
\hline 1991-1995 & 0.0145 & 0.0086 & 0.0162 & 0.0111 & 0.0158 & 0.0101 & 0.0094 \\
\hline $1996-2000$ & 0.0092 & 0.0157 & 0.0120 & 0.0119 & 0.0149 & 0.0087 & 0.0098 \\
\hline 2001-2005 & 0.0087 & 0.0106 & 0.0119 & 0.0088 & 0.0080 & 0.0088 & 0.0096 \\
\hline 2006-2011 & 0.0217 & 0.0182 & 0.0269 & 0.0179 & 0.0291 & 0.0261 & 0.0118 \\
\hline \multicolumn{8}{|l|}{$\mathrm{HS}$} \\
\hline 1981-1985 & 0.0543 & 0.0430 & 0.0561 & 0.0429 & 0.0294 & 0.0420 & 0.0500 \\
\hline 1986-1990 & 0.0797 & 0.0537 & 0.0615 & 0.0480 & 0.0657 & 0.0562 & 0.0534 \\
\hline 1991-1995 & 0.0740 & 0.0475 & 0.0898 & 0.0433 & 0.1260 & 0.0424 & 0.0511 \\
\hline $1996-2000$ & 0.0431 & 0.0549 & 0.0729 & 0.0469 & 0.0475 & 0.0433 & 0.0460 \\
\hline $2001-2005$ & 0.0489 & 0.0594 & 0.0546 & 0.0426 & 0.0473 & 0.0445 & 0.0511 \\
\hline $2006-2011$ & 0.0892 & 0.0745 & 0.0926 & 0.0541 & 0.0867 & 0.0489 & 0.0715 \\
\hline \multicolumn{8}{|l|}{$\mathrm{MC}$} \\
\hline 1981-1985 & 0.0644 & 0.0391 & 0.0454 & 0.0624 & 0.0412 & 0.0555 & 0.0551 \\
\hline 1986-1990 & 0.0764 & 0.0591 & 0.0638 & 0.0540 & 0.0626 & 0.0629 & 0.0607 \\
\hline 1991-1995 & 0.0916 & 0.0512 & 0.0939 & 0.0500 & 0.0945 & 0.0446 & 0.0568 \\
\hline 1996-2000 & 0.0612 & 0.0563 & 0.0729 & 0.0481 & 0.0413 & 0.0438 & 0.0583 \\
\hline 2001-2005 & 0.0476 & 0.0672 & 0.0774 & 0.0454 & 0.0432 & 0.0422 & 0.0578 \\
\hline 2006-2011 & 0.0799 & 0.0761 & 0.0893 & 0.0598 & 0.0676 & 0.0749 & 0.0612 \\
\hline
\end{tabular}


Table 3. Evaluations for individual models

\begin{tabular}{|c|c|c|c|c|c|c|}
\hline & GARCH1 & GARCH2 & GARCH3 & EWMA & HS & $\mathrm{MC}$ \\
\hline \multicolumn{7}{|c|}{ Panel A: At the $99 \%$ confidence level and using average absolute failure error index } \\
\hline Diversified & 0.1148 & 0.2935 & 0.2665 & 0.0153 & 0.1076 & 0.0931 \\
\hline Healthcare & 0.0905 & 0.3265 & 0.2467 & 0.0104 & 0.0858 & 0.0654 \\
\hline Hotel/Motel & 0.1330 & 0.2765 & 0.2358 & 0.0192 & 0.0969 & 0.0777 \\
\hline Industrial & 0.0889 & 0.4211 & 0.2521 & 0.0114 & 0.0746 & 0.0644 \\
\hline Office & 0.0889 & 0.2490 & 0.2409 & 0.0043 & 0.0755 & 0.0684 \\
\hline Residential & 0.0799 & 0.2514 & 0.2347 & 0.0021 & 0.0706 & 0.0603 \\
\hline Retail & 0.0938 & 0.4708 & 0.2529 & 0.0112 & 0.0806 & 0.0918 \\
\hline Average & 0.0989 & 0.3266 & 0.2475 & $0.0110^{*}$ & 0.0841 & 0.0741 \\
\hline \multicolumn{7}{|c|}{ Panel B: At the 95\% confidence level and using average absolute failure error index } \\
\hline Diversified & 0.0410 & 0.1656 & 0.1548 & 0.0232 & 0.0247 & 0.0287 \\
\hline Healthcare & 0.0221 & 0.1888 & 0.1323 & 0.0291 & 0.0132 & 0.0324 \\
\hline Hotel/Motel & 0.0472 & 0.1487 & 0.1199 & 0.0241 & 0.0178 & 0.0156 \\
\hline Industrial & 0.0207 & 0.2560 & 0.1364 & 0.0302 & 0.0095 & 0.0023 \\
\hline Office & 0.0192 & 0.1325 & 0.1269 & 0.0245 & 0.0101 & 0.0107 \\
\hline Residential & 0.0140 & 0.1342 & 0.1224 & 0.0250 & 0.0087 & 0.0103 \\
\hline Retail & 0.0265 & 0.2926 & 0.1383 & 0.0288 & 0.0157 & 0.0186 \\
\hline Average & 0.0276 & 0.1887 & 0.1334 & 0.0260 & $0.0147 *$ & 0.0174 \\
\hline \multicolumn{7}{|c|}{ Panel C: At the 99\% confidence level and using RMSRB index } \\
\hline Diversified & 0.3366 & 1.5806 & 1.5081 & 0.8687 & 0.3147 & 0.3394 \\
\hline Healthcare & 0.3083 & 1.9298 & 1.3892 & 0.8666 & 0.3133 & 0.3622 \\
\hline Hotel/Motel & 0.4051 & 1.5274 & 1.1621 & 0.8376 & 0.2732 & 0.3267 \\
\hline Industrial & 0.3351 & 2.1079 & 1.4000 & 0.8715 & 0.3347 & 0.3994 \\
\hline Office & 0.2749 & 1.6094 & 1.5488 & 0.8553 & 0.2982 & 0.3312 \\
\hline Residential & 0.2940 & 1.7443 & 1.6222 & 0.8612 & 0.3024 & 0.3475 \\
\hline Retail & 0.3574 & 2.2864 & 1.3981 & 0.8481 & 0.3428 & 0.3977 \\
\hline Average & 0.3306 & 1.8269 & 1.4331 & 0.8588 & $0.3120 *$ & 0.3581 \\
\hline \multicolumn{7}{|c|}{ Panel D: At the 95\% confidence level and using RMSRB index } \\
\hline Diversified & 0.3201 & 1.5499 & 1.5318 & 0.8674 & 0.3327 & 0.3300 \\
\hline Healthcare & 0.3292 & 1.9389 & 1.3976 & 0.8656 & 0.3490 & 0.3393 \\
\hline Hotel/Motel & 0.4171 & 1.5103 & 1.1714 & 0.8370 & 0.3058 & 0.3124 \\
\hline Industrial & 0.3455 & 2.0893 & 1.3968 & 0.8712 & 0.3823 & 0.3663 \\
\hline Office & 0.2813 & 1.5880 & 1.5284 & 0.8561 & 0.3169 & 0.3163 \\
\hline Residential & 0.2959 & 1.7480 & 1.6271 & 0.8609 & 0.3305 & 0.3253 \\
\hline Retail & 0.3606 & 2.1880 & 1.3947 & 0.8500 & 0.3989 & 0.3868 \\
\hline Average & 0.3323 & 1.8022 & 1.4358 & 0.8587 & 0.3475 & 0.3441 \\
\hline
\end{tabular}

Notes: The GARCH1, GARCH2, and GARCH3 represented GARCH models allowing for time-varying higher moments up to the second, third, and fourth moments, respectively. * denotes significance at the $1 \%$ level for the $t$-test of mean difference between the best method and second best method. 
Table 4. Model evaluations for composite models

\begin{tabular}{|c|c|c|c|c|c|c|}
\hline & \multicolumn{3}{|c|}{ Simple Composite } & \multicolumn{3}{|c|}{ RMSE Composite } \\
\hline & Composite 1 & Composite2 & Composite3 & Composite 1 & Composite2 & Composite3 \\
\hline \multicolumn{7}{|c|}{ Panel A: At the $99 \%$ confidence level and using average absolute failure error index } \\
\hline Diversified & 0.0796 & 0.1241 & 0.1147 & 0.0659 & 0.0725 & 0.0766 \\
\hline Healthcare & 0.0632 & 0.1222 & 0.0977 & 0.0470 & 0.0559 & 0.0549 \\
\hline Hotel/Motel & 0.0815 & 0.1174 & 0.1071 & 0.0638 & 0.0744 & 0.0693 \\
\hline Industrial & 0.0564 & 0.1392 & 0.0971 & 0.0454 & 0.0555 & 0.0499 \\
\hline Office & 0.0588 & 0.0974 & 0.0955 & 0.0448 & 0.0543 & 0.0534 \\
\hline Residential & 0.0546 & 0.0955 & 0.0914 & 0.0372 & 0.0435 & 0.0425 \\
\hline Retail & 0.0582 & 0.1506 & 0.0972 & 0.0441 & 0.0588 & .0517 \\
\hline Average & 0.0636 & 0.1219 & 0.0991 & $0.0488^{*}$ & 0.0589 & 0.0579 \\
\hline \multicolumn{7}{|c|}{ Panel B: At the $95 \%$ confidence level and using average absolute failure error index } \\
\hline Diversified & 0.0188 & 0.0431 & 0.0387 & 0.0304 & 0.0471 & 0.0294 \\
\hline Healtl & 0.0111 & 5 & 0.0 & 16 & 02 & .0097 \\
\hline Ho & 48 & 0 & 0 . & 89 & 24 & .0100 \\
\hline Ind & 88 & 0 & & 16 & & 0046 \\
\hline Office & 87 & 0 & & 05 & 13 & 0.0106 \\
\hline Residential & 68 & 0 & & 86 & 82 & 0.0189 \\
\hline Retail & 32 & 0.0 & & 46 & 0.0152 & 0.0111 \\
\hline Average & $0.0122 *$ & 0.0424 & 0.0263 & 0.0142 & 66 & 0.0145 \\
\hline \multicolumn{7}{|c|}{ Panel C: At the $99 \%$ confidence level and using RMSRB index } \\
\hline Diversified & 0.3792 & 0.0766 & 0.0942 & 4902 & 0.4174 & 0.3879 \\
\hline Healthcare & 0.4062 & 1341 & 3 & 329 & 0.4431 & 0.4494 \\
\hline Hotel/Motel & 0.3294 & 0.08 & 0659 & 1503 & 0.3295 & 0.3277 \\
\hline Industrial & 0.4400 & 9 & 8 & 26 & 0.4311 & 0.4213 \\
\hline Office & 45 & 1 & 6 & 40 & 0.3866 & 3940 \\
\hline Residential & 838 & 6 & 7 & 34 & 656 & 0.4666 \\
\hline Retail & 0.4119 & 0285 & 8 & 71 & 79 & 0.4392 \\
\hline Average & 0.3883 & $0.0887 *$ & 0.0924 & 63 & 0.4178 & 0.4134 \\
\hline \multicolumn{7}{|c|}{ Panel D: At the $95 \%$ confidence level and using RMSRB index } \\
\hline Diversified & 0.3897 & 0.0700 & 0.0923 & 0.4705 & 0.3881 & 0.3600 \\
\hline Healthcare & 0.4188 & 0.1227 & 0.0870 & 0.5155 & 0.4140 & 0.4209 \\
\hline Hotel/Motel & 0.3369 & 0.0813 & 0.0707 & 0.4333 & 0.3048 & 0.3054 \\
\hline Industrial & 0.4488 & 0.1392 & 0.1170 & 0.5176 & 0.4033 & 0.3958 \\
\hline Office & 0.3792 & 0.0513 & 0.0651 & 0.4705 & 0.3706 & 0.3621 \\
\hline Residential & 0.3921 & 0.0761 & 0.0752 & 0.5189 & 0.4469 & 0.4488 \\
\hline Retail & 0.4274 & 0.1682 & 0.1405 & 0.5027 & 0.4313 & 0.4147 \\
\hline Average & 0.3980 & 0.1023 & $0.0915 *$ & 0.4889 & 0.3932 & 0.3879 \\
\hline
\end{tabular}

Notes: Composite1, Composite2, and Composite3 represent composite models based on GARCH-type models (GARCH1, GARCH2 and GARCH3) combined with other models, respectively. * denotes significance at the $1 \%$ level for the $t$-test of mean difference between the best method and second best method.

Furthermore, this study examined the variation of REIT VaRs over time to check the changing trends of extreme risk. In Table 2 we divided the full sample period of 1981-2011 into six sub-periods, namely 1981-1985, 1986-1990, 1991-1995, 1996-2000, 2001-2005, and 2006-2011. The VaRs of most of the groups had recently increased, particularly in 2006-2011. That is, the investment risk of REIT stocks has been larger recently.

\subsection{Model Evaluation}

This study first assessed the individual models using the AAFE and RMSRB indicators at the 95\% and 99\% confidence levels, as illustrated in Table 3. The AAFEs of EWMA were smallest at the $99 \%$ confidence level for all property groups in Panel A. Meanwhile, at the 95\% confidence level, the AAFEs for the historical simulation were smaller in all property groups. Thus, the performance evaluations of the individual models demonstrated that the EWMA and the historical simulation were the best models for estimating REIT VaRs at the $99 \%$ and $95 \%$ confidence levels, respectively. More specially, the GARCH-type models explaining higher moments of REIT returns were not 
particularly effective. In other respects, the rankings among the three GARCH type models are interesting. The GARCH1 model ranked first, followed in second and third place by the GARCH3 and GARCH2 models, respectively. This study obtains mixed results in terms of the performance assessments of the three GARCH type models, indicating that it is not useful to consider additional information content of asset returns with regard to VaR estimation issues.

We further used the RMSRBs to evaluate the individual VaR model in Panels C and D of Table 3, suggesting that the GARCH1 model produced smaller average RMSRB than other individual models across most groups for REITs and at $95 \%$ confidence levels, and demonstrating it to be the best model for estimating REIT VaRs. However, the GARCH-type model which accounted for second and third moments (namely, GARCH2) yielded a comparatively high average RMSRB, indicating that the VaR estimation is not improved by incorporating more information regarding the higher moments of REITs returns. The historical simulation performed better at the $99 \%$ confidence levels.

As a result, based on these basic evaluations, our first enhanced method to improve the REIT VaR estimation fails. A model which contained more information content could not be shown to perform better comprehensively.

The performances of one-step-ahead forecasting of the composite models, in terms of the AAFEs and RMSRB measures, are presented in Table 4. Here Composite1, Composite2, and Composite3 represent composite models based on GARCH-type models (i.e., GARCH1, GARCH2 and GARCH3) combined with HS, EMWA, and MC models, respectively. The composite models that used RMSE weights generally had lower average AAFEs than the simple average weights at the $99 \%$ and $95 \%$ confidence levels. Furthermore, the Compositel model performs best among all the models in most groups of REITs, as shown in Panels A and B. Note that all composite models can markedly reduce failure errors compared to the individual models, as shown in Table 3 . The empirical results indicate that our attempts to use the composite methods to enhance the estimation for the REIT VaRs are successful.

Based on the RMSRBs, the composite models weighted by the simple average weight had lower bias than those weighted by the RMSE weights. In addition, compared to the individual models shown in Table 3, we found that the RMSRBs using the composite methods with a simple average weight were smaller than those obtained from the individual models at the $95 \%$ and $99 \%$ confidence levels. Specially, the Composite 2 and Composite 3 models weighted by the simple composite method significantly outperformed the others. Therefore, the empirical results indicated that the VaR calculated using the composite methods with simple average weights is significantly superior to other models evaluated in this paper.

Two improved methods which contained more information content about REIT returns have obtained different empirical results. The GARCH type models fail to increase the estimated efficiency of REIT VaRs, while the composite models enhance successfully enhance the estimated efficiency. One possible explanation for these results is that the GARCH models have incorporated some higher moments of asset returns which contain more noise from those of the third and fourth moments of asset returns. Although the composite models also contain more information included in the noises from various models, the composite models can combine, mix, or average these noises to minimize disturbances. Thus the composite models are proved to be the best models to estimate the REIT VaRs.

\section{Conclusions}

This article designs two improved methods, which included more information content regarding return characteristics, to estimate the value at risk for REITs across 122 assets during the period from 1981 to 2011 . We consider the GARCH-type models with some time-varying higher moments of asset returns, and composite methods which the GARCH-type models combined with HS, EMWA, and MC models.

Based on the one-step-ahead forecasting results, the EWMA was found to be the best among the various individual models at the $99 \%$ confidence level, while both GARCH models accounted for the second moment and the HS models performed better at the $95 \%$ confidence level. The GARCH models considered the most information regarding asset returns, the ones which account for second, third, and fourth moments were not really effective, since they frequently produced large failure errors. However, the composite models could markedly increase the accuracy of VaR estimation. Specifically, composite1 models (i.e., GARCH1 combined with HS, EMWA, and MC models) weighted using a simple average produced the smallest failure errors.

We conclude that, for REIT markets, the GARCH-type models accounting for time-varying higher moments of REIT returns are not really feasible, while the composite models are more effective in improving the VaR estimation of REITs. 


\section{References}

Bates, J. M., \& Granger, C. W. J. (1969). The combination of forecasts. Quarterly Operational Research, 20, 451-468. http://dx.doi.org/10.1057/jors.1969.103

Bollerslev, T. (1986). Generalized autoregressive conditional heteroskedasticity. Journal of Economics, 31, 307-327.

Bond, S. A., \& Patel, K. (2003). The conditional distribution of real estate returns: Are higher moments time varying? Journal of Real Estate Finance and Economics, 26, 319-339. http://dx.doi.org/10.1023/A:1022939127383

Brooks, C., \& Persand, G. (2002). Model choice and value-at-risk performance. Financial Analysts Journal, 58, 87-99. http://dx.doi.org/10.2469/faj.v58.n5.2471

Charles, Jr. W. C. (2000). Composite forecasting: combining forecasts for improved accuracy. Journal of Business Forecasting Methods and Systems, 19, 2-22.

Devaney, M. (2001). Time varying risk premia for real estate investment trusts: A GARCH-M Model. Quarterly Review of Economics and Finance, 41, 335-46. http://dx.doi.org/10.1016/S1062-9769(00)00074-0

Dias, A. (2013). Market capitalization and Value-at-risk. Journal of Banking \& Finance, forthcoming. http://dx.doi.org/10.1016/j.jbankfin.2013.04.015

Engle, F. R., \& Manganelli, S. (2004). CA-VaR: Conditional autoregressive value at risk by regression quantiles. Journal of Business and Economic Statistics, 22, 367-382. http://dx.doi.org/10.1198/073500104000000370

Engle, R. (1982). Autoregressive conditional heteroscedasticity with estimates of variance of UK inflation. Econometrica, 50, 987-1008. http://dx.doi.org/10.2307/1912773

Ewing, B. T., \& Payne, J. E. (2005). The response of real estate investment trust returns to macroeconomic shocks. Journal of Business Research, 58, 293-300. http://dx.doi.org/10.1016/S0148-2963(03)00147-4

Gordon, J., \& Tse, E. W. K. (2003). VaR: a tool to measure leverage risk. Journal of Portfolio Management, 29 , 62-65. http://dx.doi.org/10.3905/jpm.2003.319907

Granger, C. W., \& Ramanathan, R. (1984). Improved methods of combining forecasts. Journal of Forecasting, 3, 197-204. http://dx.doi.org/10.1002/for.3980030207

Harvey, C. R., \& Siddique, A. (1999). Autoregressive conditional skewness. Journal of Financial and Quantitative Analysis, 34, 465-487. http://dx.doi.org/10.2307/2676230

Hendricks, D. (1996). Evaluation of value-at-risk models using historical data. Economic Policy Review, 2, 39-69.

Komunjer, I. (2007). Asymmetric power distribution: Theory and application to risk measurement. Journal of Applied Econometrics, 22, 891-921. http://dx.doi.org/10.1002/jae.961

Kuester, K., Mittnik, S., \& Paolella, M. S. (2006). Value-at-risk prediction: A comparison of alternative strategies. Journal of Financial Econometrics, 4, 53-89. http://dx.doi.org/10.1093/jjfinec/nbj002

Lee, Y. H., \& Ou, H. L. (2010). The day-of-the-week effect and value-at-risk in real estate investment trusts. Journal of Real Estate Portfolio Management, 16, 21-28. http://dx.doi.org/10.3905/jpm.1990.409265

Leon, A., Rubio, G., \& Serna, G. (2005). Autoregressive conditional volatility, skewness and kurtosis. Quarterly Review of Economics and Finance, 45, 599-618. http://dx.doi.org/10.1016/j.qref.2004.12.020

Lu, C. L., Tse, Y., \& Williams, M. (2013). Returns transmission, value at risk, and diversification benefits in international REITs: evidence from the financial crisis. Review of Quantitative Finance and Accounting, 40, 293-318. http://dx.doi.org/10.1007/s11156-012-0274-3

Lu, C. L., Wu, S. C., \& Ho, L. C. (2009). Applying VaR to REITs: A comparison of alternative methods. Review of Financial Economics, 18, 97-102. http://dx.doi.org/10.1016/j.rfe.2008.03.001

Morgan J. P. (1996). RiskMetrics - Technical Document (4 ${ }^{\text {th }}$ ed.). New York.

Ouyang, Z. (2009). Model choice and value-at-risk estimation. Quality and Quantity, 43, 983-991. http://dx.doi.org/10.1007/s11135-007-9157-4

Serrano, C., \& Hoesli, M. (2007). Forecasting EREIT returns. Journal of Real Estate Portfolio Management, 13, 293-309.

Shi, S. M., Xu, L. D., \& Liu, B. (1999). Improving the accuracy of nonlinear combined forecasting using neural networks. Expert Systems with Applications, 16, 49-54. http://dx.doi.org/10.1016/S0957-4174(98)00030-X

Zhou, J. (2012). Extreme risk measures for REITs: A comparison among alternative methods. Applied Financial Economics, 22, 113-126. http://dx.doi.org/10.1080/09603107.2011.605752 